30. Nakao, M., Nakayama, T., and Kankura, T.: A new method for separation of human blood component. Nature New Biol., 246: 94 (1973).

31. Oski, F. A.: Glycolytic intermediates and glycolytic enzymes. Pediatrics, 44 84 (1969).

32. Paglia, D. E., and Valentine, W. N.: Evidence for molecular alteration of pyruvate kinase as a consequence of erythrocyte aging. J. Lab. Clin. Med. 76: 202 (1970).

33. Peters, J., Hopkinson, D. A., and Harris, H.: Genetic and nongenetic variation of triose phosphate isomerase (TPI) isozymes in human tissues. Ann. Hum. Genet., 36: 297 (1973)

34. Rozenszajn, L. A., Kolman, S., Shoham, S., and Gazith, J.: Glucose-6phosphate dehydrogenase isoenzymes in blood cells. Nature, 226: 862 (1970).

35. Sass, M. D., Vorsanger, E., and Spear, P. W.: Enzyme activity an indicator of red cell age. Clin. Chim. Acta, 10: 21 (1964).

36. Tarui, S., Kono, N., Nasu, T., and Nishikawa, M.: Enzymatic basis for the coexistence of myopathy and hemolytic disease in inherited muscle phosphofructokinase deficiency. Biochem. Biophys. Res. Commun., 34: 77 (1970).

Copyright 101977 International Pediatric Research Foundation, Inc.
37. Uriel, J.: Characterization of enzymes in specific immune precipitates. Ann N. Y. Acad. Sci., 103: 956 (1963).

38. Waterbury, L., and Frenkel, E.: Hereditary nonspherocytic hemolysis with erythrocyte phosphofructokinase deficiency. Blood, 39: 415 (1972).

39. Whaun, J. M., and Oski, F. A.: Characteristics of red cell phosphofructokinase (PFK): Studies of erythrocytes from newborn infants and adults. Clin. Res., 27: 603 (1969)

40. We attest that informed consent was obtained from the adult volunteers and from the parents of infants whose blood samples were used for the present study.

41. This research was supported in part by Grants from INSERM, CRL 76.5.110.1 and ATP 147537

42. The present address of Dr. C. Boyer is: Laboratoire Central d'Hématologie, Hôpital Bretonneau, rue arpeaux, 75018 Paris (France)

43. Requests for reprints should be addressed to: $A$. Kahn, Ph.D., L'institut de Pathologie Moléculaire, INSERM U129, 24 Rue du Fg St. Jacques, Paris 75014 (France).

44. Received for publication June 29, 1976

45. Accepted for publication September 16, 1976.

Printed in U.S.A.

\title{
The Immediate Ventilatory Response to Added Inspiratory Elastic and Resistive Loads in Preterm Infants
}

\author{
RODNEY B. BOYCHUK, MARY M. K. SESHIA, AND HENRIQUE RIGATTO(26) \\ Department of Paediatrics, University of Manitoba, Winnipeg, Manitoba, Canada
}

\section{Summary}

We measured the changes in tidal volume, duration of the various phases of the respiratory cycle, and peak nasal pressure during elastic and resistive loading in preterm infants. Values were calculated during the first loaded breath, when chemical drive was unchanged. Tidal volume decreased by equivalent percentages with resistive loads of 400,900 , and $2,400 \mathrm{~cm} \mathrm{H}_{2} \mathrm{O} /$ liter/sec, and elastic loads of $330,1,000$, and $3,000 \mathrm{~cm} \mathrm{H}_{2} \mathrm{O}$ liter. Infinite load was also applied (nasal occlusion). Inspiratory duration (Ti) was prolonged during resistive loading, as compared with elastic loading $(P<0.05)$. Changes in expiratory duration (Te) were not different with both loads $(P>0.05)$. Total duration of the respiratory cycle $(T)$, however, tended to increase in relation to control, more so with resistive loads. Peak nasal pressure was greater with resistive than with elastic loads $(P<0.025)$. We suggest that (1) preterm infants, like adult subjects and other animal species, increase inspiratory duration with resistive loads as compared with elastic loads; (2) $T$ of the first loaded breath tends to increase with progressively larger loads and, consequently, instantaneous frequency tends to decrease; and (3) if peak nasal pressure reflects tension developed by the respiratory muscles, then the latter does not offer the inhibitory information needed to terminate inspiration.

\section{Speculation}

Preterm infants are obligatory nose breathers. Upper airway obstruction, being common in these infants, would impose extra resistive load on respiration. Because the pattern of breathing is more affected by resistive than elastic loading, it may be that an understanding of the physiologic response to resistive loads is more important than that obtained with conventional emphasis on elastic loading.

The ability of the respiratory system to resist a change in tidal volume in response to added inspiratory loads has been used as an index of ventilatory stability $(11,15)$. There are a number of studies assessing this ability in adult subjects and animals $(4,8$, $9,17,19-21)$, but few in neonates $(1,12,13)$. Furthermore, little is known about the response to elastic and resistive loads in the same subjects $(6,16,17)$. In preterm infants such a re- 
sponse has not been studied. Because it is not unusual for these infants to present with partially occluded nostrils ("stuffy noses"), their response to resistive loads may help to further our understanding of how they control breathing during mechanical loading. We decided, therefore, to define the response of preterm infants to various inspiratory elastic and resistive loads during the first month of life. We compared tidal volume, duration of the various phases of the respiratory cycle, and peak nasal pressure of the first loaded breath with that of the preceding unloaded breath.

\section{SUBJECTS AND METHODS}

\section{SUBJECTS}

We studied 10 "healthy" preterm infants on one occasion each. Gestational age was $31.5 \pm 0.68$ weeks (mean $\pm \mathrm{SE}$ ), birth weight $1,560 \pm 124 \mathrm{~g}$, and postnatal age $8.8 \pm 2.8$ days. Seven infants were females and three were males.

\section{METHODS}

We modified our methods (18) to allow: (1) airway occlusion; (2) rebreathing; and (3) addition of elastic or resistive loads (Fig. 1).

We sampled inspired and expired gases using a fine catheter (PE 20) attached to one nostril adapter. We measured nasal pressure using another catheter (PE 200) attached to the other nostril adapter, and connected to a pressure transducer (Statham PM 50). The baby rebreathed through the nostril adapters from a bag filled with $100 \mathrm{ml}$ oxygen. The flow signal was electrically integrated to give volume. By turning a three-way stopcock, either elastic or resistive loads could be added. Elastic loads were applied by having the baby breathe from glass bottles of $300,1,000$, and $3,000 \mathrm{ml}$, the corresponding elastances being $3,000,1,000$ and $330 \mathrm{~cm} \mathrm{H}_{2} \mathrm{O} /$ /iter, respectively. Resistive loads were imposed by having the baby breathe through a syringe with 3,2 , or 1 small holes, the corresponding added resistances being 400,900 , and $2,400 \mathrm{~cm} \mathrm{H}_{2} \mathrm{O}$ liters/sec, respectively. Infinite

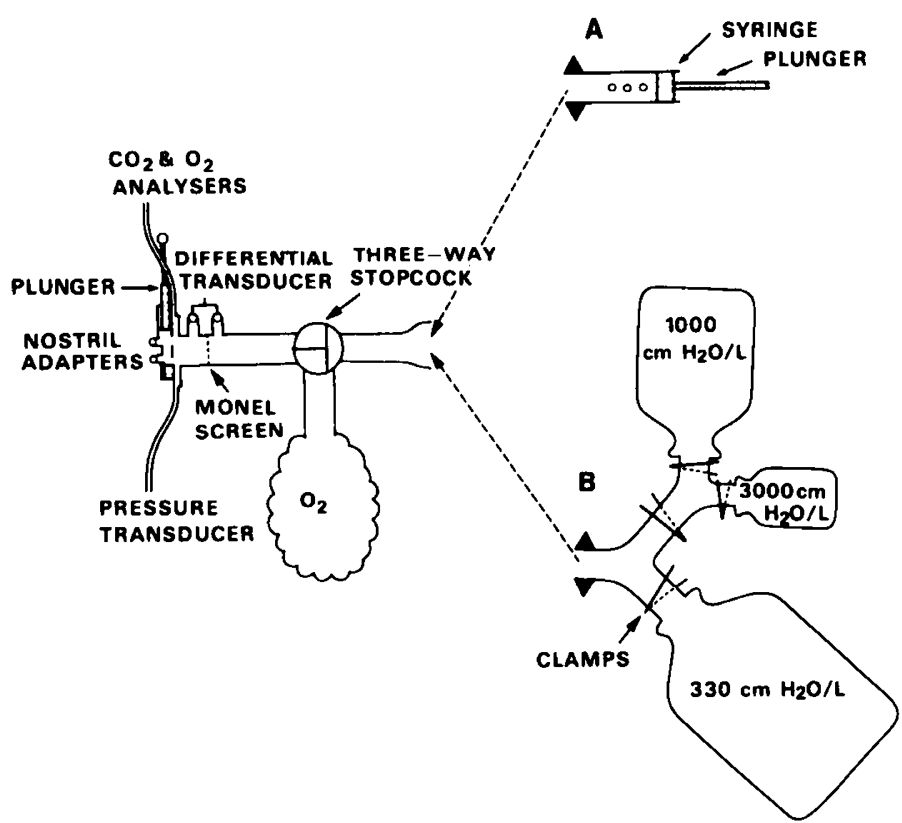

Fig. 1. Rebreathing system. Either A or B was connected to the end of the apparatus, so that resistive or elastic loads could be imposed. By advancing the plunger $(A)$, the infant breathed through progressively fewer holes and thus at a higher resistive load. By clamping the appropriate tubes $(B)$, the infant breathed from progressively smaller bottles and thus at a higher elastic load. Complete occlusion was accomplished by occluding the nostril adapters with the nostril adapter plunger. load was applied by occluding the nostril adapters with a plunger. Each load was applied for one complete breath four to six times during the study.

\section{PROCEDURE}

The procedure was explained to the mother and her written consent was obtained. All babies were studied on the Ohio Neonatal Intensive Care Unit immediately after a feed. Abdominal skin temperature was kept at $36.5 \pm 0.04^{\circ}$. Xylocaine ointment was applied lightly to the baby's nostrils and around the nostril adapters. This served to anesthetize the skin and to provide an airtight seal around the adapters. The baby's mouth was gently held closed during the study. The various loads and occlusions were applied randomly at endexpiration. The infants tolerated the procedure well and generally slept quietly throughout the study, although they tended to be more restless towards the end of the study as $\mathrm{CO}_{2}$ began to accumulate.

\section{ANALYSIS}

We chose an average of two breaths from each elastic or resistive load based on the technical excellency of loading, i.e., where the load was applied exactly at endexpiration. We measured tidal volume $\left(\mathrm{V}_{\mathrm{T}}\right)$, inspiratory duration $(\mathrm{Ti})$, expiratory duration (Te), total duration of the respiratory cycle $(\mathrm{T})$, and peak nasal pressure $\left(P_{N}\right)$ during the loaded breath and in the breath preceding occlusion (control breath). $\mathrm{Ti}, \mathrm{Te}$, and $\mathrm{T}$ were measured from the flow tracing, except during complete occlusion, when measurements were made from the pressure tracing. We compared the percentage of changes in the various phases of the respiratory cycle and in peak nasal pressure of the loaded breath over the preceding unloaded breath (control), using the paired $t$-test. We used the unpaired $t$-test to compare the percentage of changes obtained with elastic versus resistive loads in the same subjects at equivalent reductions in tidal volume.

\section{LIMITATIONS OF METHODS}

Inspiratory time and peak nasal pressure generated after occlusion seem to vary with active but not with quiet sleep (3). We have not monitored sleep state and this might have affected our results. However, our infants were rebreathing and respiration was regular preceding occlusion. We feel, therefore, that changes in our findings due to sleep state were unlikely. Furthermore, if present, errors due to sleep state changes should have affected both resistive and elastic loads, cancelling each other out.

\section{RESULTS}

When compared with the control unloaded breath, tidal volume of the loaded breath always decreased $(P<0.001)$ (Table 1). Ti was more uniformly prolonged with resistive loads $(P<$ 0.025 ) than with elastic loads. Changes in Te were variable and $T$ tended to increase with loading. Large variance, however, precluded statistical significance $(P>0.05)$. Ti, Te, and T were not significantly prolonged with complete occlusion $(P>0.05)$. When the percentage of change was compared at similar reductions in tidal volume, the percentage of prolongation in $\mathrm{Ti}$ was greater with resistive than with elastic loads $(P<0.05)$ (Fig. 2$)$. The percentage of change in Te was not different with elastic and resistive loads $(P>0.05)$, but that in T at $78 \%$ reduction in tidal volume was $(P<0.05) . P_{N}$ was greater with resistive than with elastic loads $(P<0.05)$.

\section{DISCUSSION}

The most pertinent changes in response to inspiratory elastic and resistive loading in preterm infants were: $(1)$ the more prolonged $\mathrm{Ti}$ with resistive than with elastic loads; (2) the tendency for $\mathrm{T}$ to increase with loading, more so with resistive 
Table 1. Changes in $V_{T}, T i, T e, T$, and $P_{N}$ when various elastic and resistive loads were applied to 10 preterm infants

\begin{tabular}{|c|c|c|c|c|c|c|c|c|c|c|c|c|c|}
\hline \multirow{2}{*}{ Added loads } & \multicolumn{3}{|c|}{$\mathrm{V}_{\mathrm{T}}, \mathrm{ml}$} & \multicolumn{3}{|c|}{$\mathrm{Ti}$, sec } & \multicolumn{3}{|c|}{$\mathrm{Te}, \mathrm{sec}$} & \multicolumn{3}{|c|}{$\mathrm{T}, \mathrm{sec}$} & \multirow{2}{*}{$\begin{array}{c}\mathrm{P}_{\mathrm{N}}, \mathrm{cm} \\
\mathrm{H}_{2} \mathrm{O} / \text { liter }\end{array}$} \\
\hline & $\mathrm{C}$ & L & $\%$ & C & L & $\%$ & $\mathrm{C}$ & L & $\%$ & C & L & $\%$ & \\
\hline \multicolumn{14}{|l|}{$\begin{array}{c}\text { Elastances, cm } \\
\mathrm{H}_{2} \mathrm{O} / \text { liter }\end{array}$} \\
\hline \multirow[t]{2}{*}{330} & 13.7 & $9.2^{2}$ & -33 & 0.36 & 0.36 & 0 & 0.53 & 0.52 & -2 & 0.89 & 0.87 & -2 & 2.64 \\
\hline & \pm 1.9 & \pm 1.7 & \pm 6 & \pm 0.03 & \pm 0.04 & \pm 1.4 & \pm 0.10 & \pm 0.07 & \pm 8.3 & \pm 0.11 & \pm 0.10 & \pm 4.9 & \pm 0.39 \\
\hline \multirow[t]{2}{*}{1,000} & 17.5 & $7.9^{2}$ & -55 & 0.35 & 0.37 & 6 & 0.59 & 0.57 & -3 & .94 & 0.94 & 0 & 4.03 \\
\hline & \pm 2.1 & \pm 1.4 & \pm 5 & \pm 0.04 & \pm 0.05 & \pm 6.0 & \pm 0.14 & \pm 0.14 & \pm 7.3 & \pm 0.17 & \pm 0.17 & \pm 4.1 & \pm 0.52 \\
\hline \multirow[t]{2}{*}{3,000} & 18.9 & $3.7^{2}$ & -80 & 0.33 & $0.45^{2}$ & 36 & 0.49 & 0.59 & 20 & 0.82 & 1.04 & 27 & 6.62 \\
\hline & \pm 2.9 & \pm 0.7 & \pm 3 & \pm 0.02 & \pm 0.06 & \pm 12 & \pm 0.05 & \pm 0.11 & \pm 19 & \pm 0.06 & \pm 0.13 & \pm 12 & \pm 0.85 \\
\hline \multicolumn{14}{|l|}{$\begin{array}{l}\text { Resistances, cm } \\
\qquad \mathrm{H}_{2} \mathrm{O} / \text { liter } / \mathrm{sec}\end{array}$} \\
\hline \multirow[t]{2}{*}{400} & $19.9^{3}$ & $11.3^{2}$ & -43 & 0.35 & $0.50^{2}$ & $43^{3}$ & 0.57 & 0.54 & -7 & 0.92 & 1.03 & 12 & $4.99^{3}$ \\
\hline & \pm 2.5 & \pm 1.6 & \pm 7 & \pm 0.02 & \pm 0.05 & \pm 6.9 & \pm 0.08 & \pm 0.10 & \pm 5.9 & \pm 0.10 & \pm 0.13 & \pm 5.6 & \pm 0.64 \\
\hline \multirow[t]{2}{*}{900} & 21.0 & $9.4^{2}$ & -55 & 0.36 & $0.58^{2}$ & $61^{3}$ & 0.70 & 0.61 & -13 & 1.07 & 1.13 & $6^{3}$ & $6.51^{3}$ \\
\hline & \pm 2.3 & \pm 1.0 & \pm 6 & \pm 0.03 & \pm 0.05 & \pm 11.4 & \pm 0.08 & \pm 0.07 & \pm 7.9 & \pm 0.10 & \pm 0.14 & \pm 8.4 & \pm 0.81 \\
\hline \multirow[t]{2}{*}{2,400} & 21.3 & $4.8^{2}$ & -77 & 0.33 & 0.55 & $67^{3}$ & 0.57 & 0.56 & -2 & 0.90 & 1.06 & 18 & 7.30 \\
\hline & \pm 2.0 & \pm 0.7 & \pm 3 & \pm 0.02 & \pm 0.06 & \pm 13 & \pm 0.06 & \pm 0.10 & \pm 20 & \pm 0.08 & \pm 0.16 & \pm 12 & \pm 0.99 \\
\hline \multicolumn{14}{|l|}{$\begin{array}{l}\text { Infinite load } \\
\quad \text { (occlusion) }\end{array}$} \\
\hline & 19.4 & $0.4^{2}$ & -98 & 0.32 & 0.44 & 38 & 0.53 & 0.77 & 45 & 0.88 & 1.09 & 24 & 8.32 \\
\hline & \pm 2.6 & \pm .2 & \pm 2 & \pm 0.02 & \pm 0.08 & \pm 18.8 & \pm 0.07 & \pm 0.16 & \pm 22.3 & \pm 0.07 & \pm 0.18 & \pm 18.0 & \pm 0.84 \\
\hline
\end{tabular}

' Values are means \pm SE. C: control breath; L: loaded breath.

${ }^{2} P<0.05$ relates to the significance of the difference between loaded and unloaded (control) breaths.

${ }^{3} P<0.05$ relates to the significance of the differences with added resistances and added elastances at similar reductions in tidal volume.

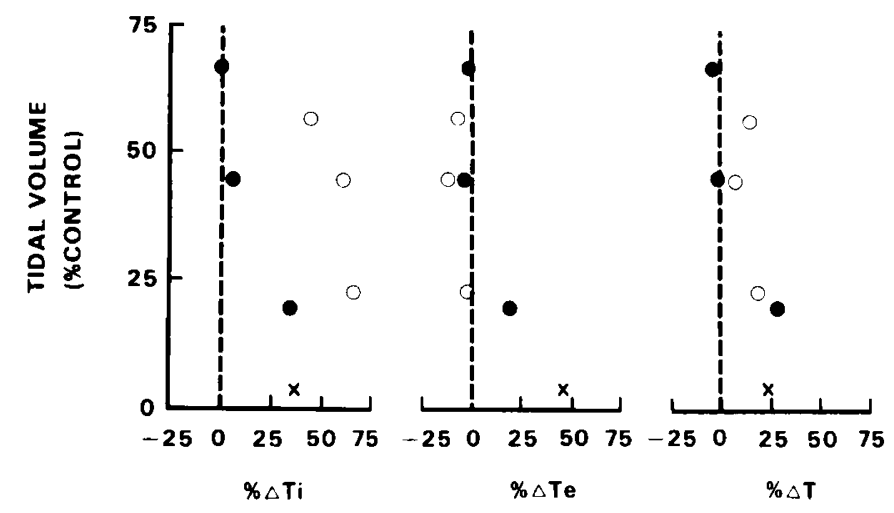

Fig. 2. Average percentage of change in $\mathrm{Ti}, \mathrm{Te}$, and $\mathrm{T}$ at reduced tidal volumes by adding elastic loads $(\Theta)$, resistive loads $(O)$, and complete occlusion $(x)$ to 10 preterm infants.

loads; and (3) the greater $P_{N}$ with resistive than with elastic loads. The tendency for $T$ to increase means that instantaneous frequency tends to decrease. The greater peak nasal pressure achieved during resistive as compared with elastic loading probably reflects greater tension developed by the inspiratory muscles. If so, this tension does not offer the inhibitory information needed to terminate inspiration.

Data in the literature are limited to the response of preterm infants to inspiratory elastic loads. Olinsky et al. $(12,13)$ found that duration of inspiration was prolonged after complete nasal occlusion, more so in preterm than in term infants. Finer et al. (5) showed greater prolongation in $\mathrm{Ti}$ with complete occlusions during quiet (non-REM) than during nonquiet (REM) sleep.

Resistive loads have not been applied to preterm infants previously. Our findings of a prolonged $\mathrm{Ti}$ with resistive loads in relation to elastic loading agree with studies in adult subjects $(6$, $17,19,21)$.

The state of consciousness seems to affect distinctively the changes in $\mathrm{Ti}$ during elastic and resistive loading. In response to resistive loading $\mathrm{Ti}$ became more prolonged during the conscious state than during the unconscious state in adult subjects (17). In response to elastic loading, however, Ti actually shortened dur- ing consciousness $(8,16,17)$. Preterm infants were asleep when studied, and therefore, somewhat unconscious. Their prolonged $\mathrm{Ti}$ with resistive loads compares well, therefore, with that in anesthetized adults, and so does their unchanged or slightly increased $\mathrm{Ti}$ with elastic loads. Unfortunately, responses have not been assessed in wakeful infants for technical reasons. Nevertheless, our observations indicate that their overall response to resistive and elastic loads may not differ substantially from that in adult subjects. As changes in $\mathrm{Ti}$ with resistive loads in conscious man move in opposite directions than those with elastic loads, the mechanisms controlling $\mathrm{Ti}$ during these two types of loading are probably qualitatively not the same.

The control of $\mathrm{Ti}$ is directed in a way of minimizing the tension, or possibly, the energy expenditure of the respiratory muscles and has been predicted previously from theoretic analyses of respiratory mechanics $(11,14)$. Although this seems plausible, the neurologic basis for this control is not established. At least four sensory systems may be involved: (1) pulmonary stretch receptors; (2) joint receptors of the rib cage; (3) tendon organs; and (4) muscle spindles of the respiratory muscles. Shannon et al. (19) measured the electric activity of medullary inspiratory neurons during resistive and elastic loading in cats. The increased rate and duration of activity of these neurons during resistive loading disappeared with vagotomy. During elastic loading no change or a decrease in activity was observed and this was not affected by vagotomy. They proposed that changes in $\mathrm{Ti}$ with resistive loads, which are flow related, are vagal dependent and have little or no diaphragm tendon organ or external intercostal inhibition. Changes in $\mathrm{Ti}$ with elastic loads, which are volume dependent, appear to be influenced by inhibition signals originating from the tendon organs. These findings suggest that a single mechanism such as lung inflation, i.e., the Hering-Breuer system, could not explain solely the differences in inspiratory changes with elastic and resistive loads. To differentiate these two loads, a control system would probably require information on tension, volume and air flow.

\section{CONCLUSION}

We measured the various phases of the respiratory cycle plus peak nasal pressure during elastic and resistive loading in pre- 
term infants. We found that: (1) Ti is more prolonged with resistive than with elastic loads; (2) $\mathrm{T}$ tends to increase with loading, more so with resistive loads; and (3) peak nasal pressure is greater with resistive than with elastic loads. These findings suggest that: (1) control of $\mathrm{Ti}$ is flow dependent; (2) instantaneous frequency tends to decrease with loading; and (3) if peak nasal pressure reflects tension developed by the respiratory muscles, the latter does not represent the inhibitory information needed to terminate inspiration.

\section{REFERENCES AND NOTES}

1. Adler, S. M., Thach, B. T., and Frantz, I. D.: Ventilatory stability of the premature infant. Pediat. Res., 9: 393 (1975)

2. Bradley, G. W.: The response of the respiratory system to elastic loading in cats. Resp. Physiol., 16: 142 (1972).

3. Bryan, A. C.: Personal communication.

4. Davies, H. W., Haldane, J. S., and Priestley, J. G.: The response to respiratory resistance. J. Physiol., 53: 60 (1919).

5. Finer, N. N., Abroms, I. F., and Taeusch, H. W., Jr.: Influence of sleep state on the control of ventilation [Abstract]. Pediat. Res., 9: 365 (1975)

6. Freedman, S., and Campbell, E. J. M.: The ability of normal subjects to tolerate added inspiratory loads. Resp. Physiol., 10: 213 (1970).

7. Freedman, S.: The effects of added loads in man: conscious and anesthetized. In: L. D. Pengelly, A. S. Rebuck, and E. J. M. Campbell: Loaded Breathing, p. 23 (Longman Canada Ltd., Hamilton, Canada, 1973).

8. Margaria, C. E., Iscoe, S., Pengelly, L. D., Couture, J., Don, H., and MilicEmili, J.: Immediate ventilatory response to elastic loads and positive pressure in man. Resp. Physiol., 18: 347 (1973).

9. McClelland, A. R., Sproule, B. J., and Lynne-Davies, P.: Functional importance of the Breuer-Hering reflex. Resp. Physiol., 15: 125 (1972).

10. McIlroy, M. B., Eldridge, F. L., Thomas, J. P., and Christie, R. V.: The effect of added elastic and non-elastic resistances on the pattern of breathing in normal subjects. Clin. Sci., 15: 332 (1956).

11. Mead, J.: Control of respiratory frequency. J. Appl. Physiol., 15: 325 (1960).
12. Olinsky, A., Bryan, M. H., and Bryan, A. C.: Influence of lung inflation on respiratory control in neonates. J. Appl. Physiol., 36: 426 (1974).

13. Olinsky, A., Bryan, M. H., and Bryan, A. C.: Response of newborn infants to added respiratory loads. J. Appl. Physiol., 37: 190 (1974).

14. Otis, A. B., Fenn, W. O., and Rahn, H.: Mechanics of breathing in man. J. Appl. Physiol., 2: 592 (1950)

15. Pengelly, L. D., Alderson, A. M., and Milic-Emili, J.: Mechanics of the diaphragm. J. Appl. Physiol., 30: 797 (1971).

16. Pope, H., Holloway, R., and Campbell, E. J. M.: The effects of elastic and resistive loading of inspiration on the breathing of conscious man. Resp. Physiol., 4: 363 (1968).

17. Read, D. J. C., Freedman, S., and Kafer, E. R.: Pressures developed by loaded inspiratory muscles in conscious and anesthetized man. J. Appl. Physiol., 37: 207 (1974).

18. Rigatto, H., and Brady, J. P.: Periodic breathing and apnea in preterm infants. I. Evidence of hypoventilation possibly due to central respiratory depression. Pediatrics, 50: 202 (1972)

19. Shannon, R., Zechman, F. W., and Frazier, D. T.: First-breath response of medullary inspiratory neurones to the mechanical loading of inspiration. Resp. Physiol., 16: 70 (1972)

20. Wiley, R. S., and Zechman, Jr., F. W.: Initial responses to added viscous resistance to inspiration in dogs. J. Appl. Physiol., 20: 160 (1965)

21. Zechman, F., Hall, F. G., and Hull, W. E.: Effects of graded resistance to tracheal air flow in man. J. Appl. Physiol., 10: 356 (1957).

22. We are grateful to Dr. V. Chernick for his invaluable comments, to Mrs. M. MacCallum and Mr. D. Cates for technical assistance, and to Mrs. M. Szajcz for typing and helping in the preparation of the manuscript.

23. Dr. Rodney B. Boychuk is a Medical Research Council Fellow.

24. Dr. Mary M. K. Seshia is a Research Fellow in Neonatology.

25. This research was supported by the Medical Research Council of Canada Grant MA-4980 and by the Children's Hospital of Winnipeg Research Foundation, Inc.

26. Requests for reprints should be addressed to: H. Rigatto, M.D., Department of Paediatrics, Women's Centre, 700 Wiiliam Ave., Winnipeg, Manitoba R3E 0Z3 (Canada)

27. Received for publication May 4, 1976.

28. Accepted for publication September 15, 1976.
Hypoglycemia pyruvate carboxylase liver mitochondria pyruvate dehydrogenase

Reye's syndrome

\title{
Deficient Activity of Hepatic Pyruvate Dehydrogenase and Pyruvate Carboxylase in Reye's Syndrome
}

\author{
BRIAN H. ROBINSON, ${ }^{(25)}$ D. GRANT GALL, AND ERNEST CUTZ \\ Departments of Paediatrics, Biochemistry, and Pathology, University of Toronto; Research Institute, The Hospital \\ for Sick Children, Toronto, Ontario, Canada
}

\section{Summary}

The activity of certain hepatic enzymes involved in carbohydrate metabolism was measured in postmortem samples from six cases of Reye's symdrome. The activities of the two exclusively extramitochondrial enzymes, glucose-6-phosphatase and fructose-1,6-diphosphatase, were all within the normal range. Activities of pyruvate carboxylase and pryuvate dehydrogenase, both of which are exclusively mitochondrial enzymes, were below levels shown by control tissue in every case, the average being $21.7 \%$ of the lowest control value for pyruvate carboxylase and $11.6 \%$ of that for pyruvate dehydrogenase. Impaired pyruvate metabolism appears to be another feature in Reye's syndrome.

\section{Speculation}

The hypoglycemia and lactic acidemia frequently observed in Reye's syndrome are due to decreased activity in the mitochondria of pyruvate carboxylase and pyruvate dehydrogenase, respectively.

Reye's syndrome exhibits a number of features which are indicative of gross hepatic damage including elevated blood ammonia $(1,10)$ and serum glutamic oxalic transaminase (2), hypoglycemia (15), and clotting abnormalities (5). At the same time, liver tissue from patients with Reye's syndrome demon- 